\title{
LORELAI: UMA PRINCESA ENTRE O MARAVILHOSO E A MODERNIDADE
}

Luciana Morais da Silva

Luana Castro dos Santos Braz

O conto “Lorelai”, escrito pelo galego Xosé Luís Méndez Ferrín, inicia-se com a chegada de uma jornalista em um povoado com a finalidade de saber um pouco sobre aquela população e seu reinado, sendo recebida por Aba Upseig, ama da princesa Lorelai, que lhe contou um pouco sobre o reino e a triste história da princesa, que sumira exatamente há três anos.

A menina desde pequena era diferente das princesas dos contos maravilhosos que são descritas com uma beleza única e esplendorosa. A jovem era muito feia e possuía o corpo deformado como de uma baleia: “(...) Lorelai era feia, horribelmente feia (...). O corpo da princesa era terrivelmente grosso e deforme." (MÉNDEZ FERRÍN, 1993: 56-57). Porém como era pequena não percebera a diferença, até porque sempre estava sozinha: "xogaba sempre soa e non miraba nenas da súa edade pra facer comparanza da deformidade.” (MÉNDEZ FERRÍN, 1993: 57). Encontrando-se, então, fora dos padrões de beleza ditados por seu local de origem, sua vila, a jovem acaba vítima de um ideal de beleza, ou seja, a princesa tornou-se uma prisioneira de sua feiúra, já que ela mesma não gostava de sua aparência: "ficoulle o sentimento en carne viva, decatouse plenamente da súa fealdade e sofriu, sofriu...” (MÉNDEZ FERRÍN, 1993: 57). Trecho em que se nota a angústia da personagem devido a repulsa por si mesma, ou seja, seu sofrimento pela ausência de formas físicas harmônicas.

Fazendo-se uma comparação com os contos maravilhosos tem-se uma princesa solitária que em meio às suas tristezas não encontra uma mão amiga nem de animais ou seres mágicos para auxiliá-la, mas apenas o auxílio de seu príncipe, marcando uma dessemelhança entre Lorelai e a magia dos contos maravilhosos, pois a jovem além de feia não demonstra o menor envolvimento com os acontecimentos insólitos e mágicos tão caros aos contos. Nesta narrativa, de Méndez Ferrín, a princesa apresenta-se feia e horrenda sem sofrer nenhuma maldição, ela sofre por seus problemas, tendo como um elemento mágico apenas seu sorrir, porém sua terra está permeada de traços das narrativas paradigmáticas do gênero Maravilhoso. De acordo com Luís Flávio Sieczkowsk, 
Méndez Ferrín traz para a narrativa contemporânea o cenário galego, que se d estaca não só por ter sido, desde suas origens, uma região destacadamente agrária - donde a passagem da viajante pelos trigais -, mas também por ter sido envolvido num clima de magia e de mistério, temas germinados pelas inesgotáveis peregrinações a Santiago de Compostela. (2004: 78)

Em Lorelai há, então, a exaltação da cultura galega rememorando a origem e constituição do povo, indicando um desejo do autor de dar à narrativa contemporânea a beleza do cenário galego.

Quando Lorelai faz dezessete anos percebe sua deformidade porque nenhum rapaz se interessava por ela e resolve construir uma torre para viver e defender-se de sua "feiúra", até que aparecesse um homem que a amaria do jeito que ela era e viesse salvala daquela situação: “Vella Aba, agora xa teño onde ocultar a miña vergoña'. (...) 'Miña raíña, ¿e cando sairedes do cilindro?'. Contestoume: 'Só cando un home mo pida, pra me levar coil”. (MÉNDEZ FERRÍN, 1993: 57) Assim, Lorelai permaneceu naquela torre, até o dia que um forasteiro chegou ao povoado levando-a embora da vila sem deixar nenhuma notícia. Há, portanto, uma releitura dos grandiosos salvamentos típicos dos contos maravilhosos, já que um jovem a resgata de seu infortúnio, liberando-a de sua "maldição".

Depois de três anos "sumida", para seu povo, Lorelai retorna e após ouvir toda sua história revela quem é, e relata que o homem que a levou embora da vila fora um médico, o qual a tratou transformando-a numa bela mulher, com quem posteriormente casou-se. E para provar que era verdadeiramente a princesa Lorelai, a bela jovem dá o sorriso que encantava a todos da vila. As pessoas da vila reconheciam a princesa não por sua aparência, mas pelo seu sorriso encantado: "Todos no pobo coñecemos o sorriso de Lorelai...” (MÉNDEZ FERRÍN, 1993: 59).

$\mathrm{Na}$ narrativa encontram-se alguns eventos insólitos e, numa classificação bem ampla, insólito expressa tudo o que é desusado, incomum, não freqüente, sobrenatural, incerto, raro, extraordinário, excepcional, inusitado, extravagante, excêntrico, nãohabitual, esdrúxulo etc., por fim, o que rompe ou frustra as expectativas do senso comum vigente.

O insólito tem como conceito na narrativa tudo o que estremece o previsível ou indiscutível, a partir de um olhar comprometido com a realidade cotidiana ou mesmo da ordenação social. Tais eventos incomuns rompem com o humano ou o natural, não 
pertencendo ao habitual e com o extraordinário apresentando-se para além da ordem. $\mathrm{O}$ insólito representa-se por um conjunto de fatores da narrativa que marcam os textos devido a sua presença, enquanto desempenha uma compreensão diversa do sólito, formando assim, um universo em que as verdades do mundo familiar, previsíveis dos leitores reais, seres do cotidiano, estariam modificadas.

A presença de eventos insólitos pode ser percebida, de modo sobrenatural, no sorriso de Lorelai, com uma beleza que está para além do comum, do natural, tanto que todos da vila ficam maravilhados ao vislumbrar seu sorriso: "O pobo da vila íamola visitar pola súa festa, e ela amostraba pola xaneliña o seu sorrir, e a lus dil abríase sóbor de nós, que ollabamos abraiados e de xoenllos, o milagre...” (MÉNDEZ FERRÍN, 1993: 57). Para Sieczkowsk o escritor, Méndez Ferrín, anuncia e desenvolve uma personagem cuja força maior advém de um sorriso arrebatador. (Cf. 2004: 77). Seu sorriso que iluminava toda a vila e maravilhava todos ao seu redor, a princípio, demonstra-se como um simples sorrir, porém no decorrer da narrativa nota-se uma magia envolta no sorriso da jovem Lorelai, o qual tinha o poder de dar luz a tudo que estava à sua volta, causando não só espanto em seus súditos como também admiração.

O conto revisita, portanto, o gênero da tradição, Maravilhoso, contendo marcas significativas deste, caracterizando-se pela incorporação de eventos típicos do gênero, como: a dinastia de Lorelai, ou seja, sua descendência; seu reino e o ambiente telúrico que a cercava; a torre de marfim construída ao seu redor; a espera do cavaleiro salvador, bem como, a chegada de Fael envolta em mistério. Para Le Goff (1983), “As manifestações do maravilhoso parecem muitas vezes sem ligação com a realidade cotidiana, mas revelam-se dentro dela" (LE GOFF, 1983: 25). O mistério em torno de Fael, bem como a torre, a princesa aprisionada, com um sorriso "máis belo que o mencer” (MÉNDEZ FERRÍN, 1993: 56) são elementos típicos do gênero Maravilhoso que para aquele mesmo autor, é "um contrapeso à banalidade e à regularidade do quotidiano" (LE GOFF, 1983: 24).

A narrativa Lorelai enquadra-se ainda na estrutura básica dos contos maravilhosos. Podem-se destacar cinco principais: aspiração (ou designo); viagem; obstáculos (ou desafios); mediação auxiliar e conquista do objetivo.

O designo pode ser considerado que "Toda efabulação tem, como motivo nuclear, uma aspiração ou designo, que levam o herói (ou heroína) à ação." (COELHO, 2000: 100). Ou seja, quando são mostradas as dificuldades do herói ou heroína 
vinculado à realidade, como estados de carência, penúria, conflitos, etc., que desequilibram a tranqüilidade inicial. No conto, Lorelai projeta todo seu conflito em sua aparência, passando por todo processo de angustia e carência que viveu em toda a sua fase de amadurecimento.

A viagem é outro aspecto presente, pois "A condição primeira para a realização desse designo é sair de casa, o herói empreende uma viagem ou se desloca para um ambiente estranho, não-familiar." (COELHO, 2000: 100). Essa ruptura ocorre quando Lorelai desliga-se de sua vida concreta, sai da proteção e mergulha no completo desconhecido, inicialmente quando ela tranca-se na torre e conclui-se no momento que o cavaleiro aparece e a leva embora: “Aquela noite. Fael preguntoulle á princesa: ¿Queredes deixar de ser un monstro?'. E ela contestou que si. 'Pois logo - pediulle il entrade no coche e víndevos comigo'. Fóronse os dous a Orvia." (MÉNDEZ FERRÍN, 1993: 58). Essa viagem é o principal passo para sua felicidade.

Já no desafio ocorre “À realização pretendida: ou surgem obstáculos aparentemente insuperáveis que se opõem à ação do herói (heroína)." (COELHO, 2000: 100). Lorelai não tinha mais esperança de encontrar um pretendente, pois muitos príncipes foram à busca da princesa para pedir-lhe em casamento, mas "En fin, unha chea de iles, pro cando sabían, digo, o do corpo da princesa..., fuxían coma cervos." (MÉNDEZ FERRÍN, 1993: 58), e deixando Lorelai completamente sem perspectiva.

O quarto aspecto é quando "Surge sempre um mediador entre o herói (heroína) e o objetivo que está difícil de ser alcançado; isto é, surge um auxiliar mágico, natural ou sobrenatural, que afasta ou neutraliza os perigos e ajuda o herói a vencer." (COELHO, 2000:100). O objetivo de Lorelai era ser formosa ou pelo menos normal como qualquer moça e seu maior mediador foi o cavaleiro, que trouxe para a moça a possibilidade de ser bonita, por ser um cirurgião, "Pois sei que aquil cabaleiro era o Dr. Nesjkllou Fael, que ouviu falar do caso de Lorelai e quixo curala...” (MÉNDEZ FERRÍN, 1993: 58).

Por último tem-se a conquista onde "Finalmente o herói conquista o almejado objetivo." (COELHO, 2000: 100). Finalmente Lorelai retorna a vila, linda e casada com o Doutor que a "curou", tornando-se a rainha e seu marido rei daquele local.

A jovem dama vivia em uma gigantesca torre de marfim próxima a um rio e cercado por um bosque, local em que chegavam cavaleiros pretendentes à mão da jovem que habitava a torre, elemento próprio dos contos de fadas, porém a rejeitavam, dialogando com uma prática pouco comum, ou extraordinária para o pacto que se 
estabelece com o "leitor-modelo" (ECO, 1994: 14) de contos maravilhosos. Afinal, o conto Lorelai devido a sua estruturação e ambiente próprio dos contos maravilhosos deveria apresentar cavaleiros determinados a salvar a jovem buscando manter sua integridade física, bem como, moral, entretanto viram-lhe as costas, deixando-a só, destinada ao sofrimento. Talvez a feiúra da jovem compare-se aos espinhos que envolvem o castelo da "Bela adormecida" (versão Disney), porém o motivo para a desistência dos jovens e a persistência do pré-destinado de Lorelai indica uma falha dos primeiros cavaleiros, visto que não havia barreira física e sim moral, pois o homem que se tornasse esposo de Lorelai deveria vê-la por sua beleza interior, transformando-a posteriormente por fora.

Adriana Silva em seu artigo "O Maravilhoso na Composição da História Memorial do Convento" conta toda a trajetória do gênero maravilhoso e esclarece que

O maravilhoso esteve presente em vários períodos e culturas e sempre fez parte da literatura do sobrenatural. Confundido com milagre (miraculosus) e magia (magicus), na Idade Média, e, depois, com fantástico, nos séculos XIX e XX, foram necessários alguns séculos de desenvolvimento do maravilhoso para que a crítica o definisse, considerando-o como um gênero literário. Assim, ao acompanhar diferentes períodos históricos, o maravilhoso passa por uma variedade de transformações conceituais no decorrer de seu desenvolvimento, responsáveis por sua singularidade enquanto componente narrativo. (SILVA, 2006: 2)

Ela ainda descreve em seu artigo o momento em que Todorov discorre que o maravilhoso como gênero na segunda metade do século XX é definido a partir das relações de contiguidade que mantém com seus gêneros vizinhos, o fantástico e o estranho.

Para Todorov (1992) o fantástico guia leitor e personagens a experimentar uma hesitação proveniente de um acontecimento aparentemente sobrenatural que rompe com as leis naturais. Deste modo, ele coloca a hesitação do leitor como categoria do fantástico, pois tanto a fé absoluta, marca do Maravilhoso, como a incredulidade total, traço do estranho, distancia-se do mundo fantástico. Nesse sentido, o autor não faz menção a um leitor particular, mas a uma função de leitor, que é encontrada implícita no texto, no qual a hesitação pode ser ou não representada por alguma personagem no interior da obra. 
Todorov situa o estranho e o maravilhoso como gêneros vizinhos do fantástico limitando este gênero e dividindo-o em três subgêneros: o fantástico puro, o fantástico estranho e o fantástico maravilhoso. O primeiro seria "aquele que separa o fantásticoestranho do fantástico maravilhoso; corresponde perfeitamente à natureza do fantástico, fronteira entre os dois vizinhos." (TODOROV, 1992: 51), o fantástico-estranho equivale aos "acontecimentos que parecem sobrenaturais ao longo de toda a história, no fim recebem uma explicação racional.” (TODOROV, 1992: 51) e o fantástico maravilhoso se caracteriza "pela existência exclusiva de fatos sobrenaturais, sem implicar a reação que provoquem nas personagens." (TODOROV, 1992: 53). Sendo assim, observa-se que no fantástico estranho, o sobrenatural é esclarecido racionalmente ou é considerado como resultado da imaginação, enquanto que, no fantástico maravilhoso, acontece uma aprovação do sobrenatural, que passa a ser justificado no conto.

Em seu livro Todorov ainda explica que a manifestação do estranho se dá quando os fatos descritos podem ser explicados pelas leis da razão, mas que são "de uma maneira ou de outra, incríveis extraordinários, chocantes, singulares, inquietantes, insólitas e que por esta razão, provocam na personagem e no leitor reação semelhante àquela que os textos fantásticos nos tornam familiar.” (TODOROV, 1982: 53). No maravilhoso puro, os eventos não são explicados, não ocorrendo qualquer reação das personagens ou do leitor diante dos elementos insólitos, os eventos inesperados são parte do cotidiano, sendo até mesmo buscados. Ele ainda delimita o maravilhoso puro, distinguindo-o de outros tipos de maravilhoso por meio da analise de narrativas em que o sobrenatural recebe um esclarecimento e proporciona as variedades do gênero, não correspondentes ao maravilhoso puro: o hiperbólico, o exótico, o instrumental e o científico.

No maravilhoso hiperbólico "Os fenômenos não são aqui sobrenaturais a não ser por suas dimensões, superiores às que nos são familiares.” (TODOROV, 1982: 60), ou seja, os fatos não se caracterizam como sobrenaturais, no sentido de serem provocados pelos deuses, somente suas dimensões apresentam-se como excessivas. O maravilhoso exótico é semelhante ao maravilhoso hiperbólico,

Narram-se aqui acontecimentos sobrenaturais sem apresentá-los como tais; supõe-se que o narrador implícito desses contos não conheça as regiões onde se desenrolam os acontecimentos; por conseguinte, não tem motivos para colocá-los em dúvida. (TODOROV, 1982: 61). 
Nota-se então que os eventos insólitos encontrados no maravilhoso exótico são apresentados como naturais pelo narrador.

O maravilhoso instrumental caracteriza-se pela ocorrência de "aperfeiçoamentos técnicos, irrealizáveis na época descrita, mas no final das contas perfeitamente possíveis.” (TODOROV, 1892: 62). O maravilhoso instrumental situa-se próximo do maravilhoso científico que surgira no século XIX (que depois passou a nomear-se ficção científica). Neste maravilhoso, "O sobrenatural é explicado de uma maneira racional, mas a partir de leis que a ciência contemporânea não reconhece." (TODOROV, 1892: 63).

Para Filipe Furtado, em “A construção do Fantástico na narrativa” (1980), o Maravilhoso estabelece um universo em que as categorias do empírico (baseada na experiência) foram alteradas ou eliminadas não aceitando, por imediato, uma explicação lógica que possibilita da restauração do real. Assim sendo, pode-se concluir que há um texto "honesto", cujo receptor aceita a manifestação do insólito como uma constante de verdade:

No Maravilhoso não se verifica sequer a tentativa de fazer passar por reais os acontecimentos insólitos e o mundo mais ou menos alucinado em que eles têm lugar. Estabelece-se, deste modo, com o que um pacto tácito entre o narrador e o receptor do enunciado: este deve aceitar todos os fenômenos nele surgidos de forma apriorística, como dados irrecusáveis e, portanto, não passíveis de debate sobre sua natureza e causas. Em contrapartida, a narrativa não procurará levá-lo dolosamente a considerar possível o sobrenatural desregrado que lhe propõe, mostrando-lhe desde cedo que a fenomenologia nela representada não tem nem pretende ter nada de comum com o mundo empírico. (1980: 35).

Observa-se nas atitudes de Lorelai uma mistura entre a princesa a ser resgatada, composto historicamente, e os conflitos de uma jovem contemporânea. No entanto, o fascínio frente a uma nova (situação) não remete nenhum questionamento acerca do que fazer, mediante ao futuro que lhe espera, pois ela era alguém que temia, sofria, chorava, ou seja, alguém que estava além de sua época e mesmo sendo princesa, não pode fazer nada para mudar sua condição física e ao chegar alguém de fora muda completamente a sua vida.

Le Goff em seu estudo sobre o maravilhoso na Idade Média mostra-o como originário do termo latino mirabilia, cujo radical mir comporta algo de visivo, 
caracterizando-se como um olhar. Chiampi também procura etimologicamente a significação de maravilhoso, fundamentando-se numa ausência de contradição com o natural. Segundo a autora, mirabilia significa maravilha, em oposição às naturalia, sendo da mesma origem do verbo mirare (mirar), que significa o ato de olhar com intensidade, assinalando um grau excessivo e insólito do humano, uma dimensão de beleza ou de perfeição que pode ser almejada pelos homens. É o maravilhoso hiperbólico, proposto por Todorov, que conserva o humano em sua essência, distinguindo-se dele apenas no nível quantitativo.

Por outro lado, Chiampi afirma que o verbo mirare pode sugerir também miragem, engano dos sentidos, ou milagre, de sentido contrário à ordem natural, compondo, neste caso, o maravilhoso sobrenatural, que difere do humano na sua própria essência. Este maravilhoso resulta da intervenção dos seres sobrenaturais, divinos ou legendários (deuses, anjos, demônios, gênios e fadas) e corresponde ao "miraculosus" apresentado por Le Goff. Há nos textos pertencentes a este gênero uma sensação de fascínio frente às irrupções insólitas, cotidianas aos personagens.

Selma Calasans através do Dicionário Etimológico Nova Fronteira da Língua Portuguesa, mostra que:

O termo maravilhoso é derivado de maravilha, que vem do latim marabilia, um nominativo neutro, plural de mirabilis. Refere-se a ato, pessoa ou coisa admirável, ou a prodígio. Na teoria literária, porem, é um termo historicizado. Chamamos de maravilhoso a interferência de deuses ou de seres sobrenaturais na poesia ou na prosa (fadas, anjos, etc.). (RODRIGUES: 1988: 54).

A principal característica do Maravilhoso é a existência e a procura de fatos sobrenaturais, independente da reação dos personagens em frente a esse fato. $\mathrm{O}$ episódio em que Lorelai sorri e ilumina toda vila torna-se algo sobrenatural: "e Lorelai sorriu por primeira vez na tarde, enchéndose toda a venta de lus". (MÉNDEZ FERRÍN, 1993: 59)

Nesse sentido, percebe-se que a principal marca do Maravilhoso é a naturalização do insólito, ou seja, a ocorrência dos eventos sobrenaturais, não provocarem nenhuma reação nas personagens ou no narrador, que não precisa ser necessariamente autodiegético ou homodiegético, e, por conseguinte, nem no leitor, pois os elementos insólitos estariam inseridos em um universo em que "tudo" é 
possível. O sorriso de Lorelai e a luz que é irradiada dele podem ser interpretados como um milagre pelo fato de serem a coisa mais linda presente na princesa.

O conto abordado apesar de ter um toque de modernidade, pelo fato de uma princesa dirigir um carro e ter uma profissão, além de fugir completamente dos padrões de beleza de uma legítima princesa, rememora os contos de fadas. Esses são:

de natureza espiritual/ético/existencial. Originou-se entre os celtas, com heróis e heroínas, cujas aventuras estavam ligadas ao sobrenatural, ao mistério do além-vida e visavam à realização interior do ser humano. Daí a presença da fada, cujo nome vem do termo latino "fatum", que significa destino. (COELHO, 2000:173).

Todorov relaciona o maravilhoso aos contos de fadas, sendo "uma variedade do maravilhoso e os acontecimentos sobrenaturais aí não provocam qualquer surpresa: nem no sono de cem anos, nem no lobo que fala, nem nos dons mágicos das fadas." (TODOROV, 1982: 60).

No conto de fadas Rapunzel (versão dos irmãos Grimm), por exemplo, a protagonista da história era prisioneira em uma torre com a diferença de ser contra sua vontade, afinal a bruxa a enclausurou quando ainda era pequena, enquanto Lorelai aprisionou-se para esconder sua "feiúra". Ocorre ainda uma associação entre os príncipes, uma vez que o forasteiro resgatou Lorelai da torre e a libertou de toda tristeza e em Rapunzel, ela só consegue se livrar da maldade da bruxa depois que conhece o príncipe.

As semelhanças entre Lorelai e Rapunzel, tornam-se mais fortes devido à presença do evento insólito nos contos, pois a primeira possui um sorriso que iluminava todo o povo: "O seu sorriso..., se ela sorrí todos a recoñeceremos..., ninguém pode sorrír coma Lorelai.” (MÉNDEZ FERRÍN, 1993: 59). Já em Rapunzel, ocorre quando ela é levada para o deserto vivendo uma vida miserável e infeliz, suas lágrimas tornam-se milagrosas, pois o príncipe ao ficar cego por cair da torre quando fora visitar sua amada, e, encontrar a bruxa que lhe lança uma maldição, e, ainda cair em cima de uma sarça é curado pelas lágrimas de Rapunzel. Narra-se então o encontro: "Enlaçou-o com os braços, e chorou. Duas dessas lágrimas caíram nos olhos do príncipe, e de repente ele passou a ver como antes, claramente.” (TATAR, 2004: 117)

$\mathrm{Na}$ narrativa, de Méndez Ferrín, nota-se que não há marcas que comprovem ou que desmereçam a existência de um cavaleiro armado e generoso em seu coração, dando 
ao homem que demanda salvar Lorelai um caráter contemporâneo, mas permeado pela benevolência e força dos cavaleiros, como em Rapunzel. O bom jovem, salvador de Lorelai, não se constitui propriamente como um cavaleiro valoroso e enamorado pela dama, porém sua chegada é envolta em mistério, até mesmo com certa magia, a qual povoa o imaginário medieval presente nas narrativas canônicas do Maravilhoso, faltando-lhe apenas o brandir de espadas e o glorioso animal, seu companheiro de batalhas. Entretanto, há a descrição de um “coche”, um carro, imponente e grandioso, o qual dá a chegada de Fael uma nova roupagem, porém com as mesmas características da chegada dos príncipes em seus cavalos.

O homem chega à terra de Lorelai em um carro repleto de efeitos e retira a princesa de sua "prisão". Apesar de não chegar montado em um cavalo, o homem mascarado enfrenta o empecilho e a salva, dialogando com as características dos cavaleiros medievais, corajosos e virtuosos. No conto se observa a presença desse homem como um herói, rememorando as narrativas que apresentam a temática da Demanda do Santo Graal, o herói, determinado, busca a aventura, uma vez que não teme por sua vida, como um ser imune às investidas maléficas ou demoníacas e o cavaleiro surge para salvar a princesa de todo sofrimento, trazendo alegria a sua vida e não foge como os outros príncipes.

Sendo assim, nota-se que o herói é movido por sua confiança em uma força superior que o guia, uma vez que "O destino do homem está traçado por Deus, a do herói também. Só existe um modo de vida possível, aquela originária estabelecida pela vontade divina." (PALMA, 2004: 23). Não se observa a presença divina no conto, porém percebe-se a busca pela aventura para conquistar seus objetivos principalmente quando o cavaleiro aparece para levar Lorelai, salvando-a daquele destino cruel, assim como acontece nas narrativas medievais em que o herói faz de tudo para proteger sua amada sendo sempre guiado pelo destino.

Como pôde ser observada a atitude de Lorelai em enclausurar-se e depois ir embora por três anos com Fael indicam uma princesa preocupada consigo e não com o bem comum do povo, determinada a salvar-se, corroborando com a assertiva de Berman

Homens e mulheres modernos podem muito bem ser levados ao nada, carentes de qualquer sentimento de respeito que os detenha; livres de medos e temores estão livres para atropelar qualquer um em seu caminho, se os interesses imediatos assim o determinarem. (BERMAN, 1987: 112). 
Lorelai não pensou em seu povo ao deixar a vila com seu cavaleiro, queria somente livrar-se daquele sofrimento que a cercava e encontrou naquele forasteiro um escape para resolver o problema que a assolava, não pensando duas vezes em partir com uma pessoa estranha e não percebendo que deixaria sua vila sem um líder indo embora para solucionar seus problemas. Berman ainda afirma que "A moderna humanidade se vê em meio a uma enorme ausência e vazio de valores, mas ao mesmo tempo, em meio a uma desconcertante abundância de possibilidades." (BERMAN, 1981: 21).

$\mathrm{Na}$ narrativa a princesa sentia-se totalmente humilhada por ser desprezada por vários príncipes, mas em meio ao inesperado surge-lhe uma abundância de possibilidades, pois ela via a probabilidade de mudar a sua vida por completo, não temendo e nem pensando em voltar atrás em sua decisão. A jovem devido a sua angústia viu-se disposta a enfrentar o incógnito de ser "resgatada" de sua torre por um homem encapuzado e desconhecido, mas que lhe proporcionasse segurança ao garantirlhe um futuro, deixando de ser "um monstro": "Fael preguntoulle á princesa: ¿QQueredes deixar de ser un monstro?’ E ela contestou que si.” (MÉNDEZ FERRÍN, 1993: 58).

Assim como Lorelai é apresentada fora dos padrões de beleza, em geral, encontrados na descrição das princesas dos contos de fadas, já exemplificado, a sociedade também se mostra bem contrária a muitas formas de beleza, pois para uma jovem ser considerada bela precisa enquadrar-se nos padrões estabelecidos pela sociedade em que se insere, o que acaba tornando-a, assim como, os membros de uma sociedade em prisioneiros da beleza que não os corresponde, fazendo com que as pessoas enclausurem-se em suas torres de marfim a espera de alguém que as salve ou que os paradigmas se modifiquem.

Berman afirma que "Não só a sociedade moderna é um cárcere, como as pessoas que aí vivem foram moldadas por suas barras; somos seres sem espírito, sem coração, sem identidade sexual ou pessoal - quase podíamos dizer: sem ser." (BERMAN, 1987: 27). Vê-se assim, que a sociedade é um cárcere, bem como, os paradigmas estabelecidos pelos membros dessa coletividade, os grupos pertencentes a uma determinada comunidade, acabam por estabelecer modelos a serem seguidos, os quais nem sempre correspondem à realidade da maioria, indicando uma característica a qual se almeja chegar, que, porém pode ser uma realidade distante ou impossível, a qual causa na princesa Lorelai dor e sofrimento, já que esta se fecha em "seu mundo", 
buscando resguardar-se dos olhares que a condenavam, esperando, enfim, a magia do amor que a retiraria da clausura para posteriormente inseri-la em um mundo onde ela pudesse ser desvinculada de sua feiúra anterior.

É evidente na narrativa ferriniana algo mágico que envolve os cenários e até mesmo as personagens, apesar da constante aparição e reelaboração de elementos próprios à contemporaneidade. Consoante Sieczkowski, Lorelai é uma mulher da terra, que vive o papel da mulher moderna perfeitamente adaptada à era da velocidade. (Cf. 2004: 78). "Pasaba o automóbel de ela bruando coma un rinoceronte desbocado." (MÉNDEZ FERRÍN, 1993. 55). A protagonista entra em sua vila em um carro, dirigindo-o, sendo este um traço da modernidade, visto que uma mulher chegar a um lugar em um carro é algo próprio da sociedade contemporânea. O carro sendo dirigido por uma jornalista é uma clara representação da "evolução em marcha" (CHEVALIER Apud SIECZKOWSKI, 2004: 78). A entrada de um carro no ambiente telúrico da vila de Lorelai causa um contraste entre o mundo agrário e a estrada para o automóvel. "Assim, o cenário apresenta um contraste entre o aspecto rudimentar dos trigais e o brilhantismo da máquina. Passado e presente têm encontro marcado na narrativa." (SIECZKOWSKI, 2004: 78-79)

Além disso, a jovem Lorelai não é salva por um feitiço ou por uma magia própria das narrativas canônicas do Maravilhoso, mas sim por uma "cura" proporcionada por um tratamento encontrado por meio da medicina, isto é, através de uma "mágica" moderna. Nota-se, desta forma, que a narrativa de Ferrín apresenta uma jovem que cresceu confrontando-se com sua feiúra, que, porém superou sua deformidade física por meio de uma cirurgia propiciada pelo advento da modernidade.

$\mathrm{O}$ conto passa-se em uma vila cercada por um ambiente maravilhoso, no qual vive a jovem Lorelai, esta descendente da classe de reis e rainhas, traços próprios do Maravilhoso, dotados de pureza de coração e crença no destino dos retos, em que a jovem encastela-se, crente em seu fado, afinal apenas um homem bom, ou seja, um cavaleiro poderia ou seria capaz de salvá-la.

Percebe-se, assim, a força do destino presente na narrativa, pois Lorelai não poderia ser considerada um ícone de beleza e para sua felicidade o "príncipe" que a resgata da torre é tão logo, um cirurgião plástico, que para ela seria a pessoa ideal ou mais indicada para resolver seu problema. Segundo Sieczkowski, 
O médico traz o remédio para o seu malefício, proporcionandolhe a grande chance de se tornar um ser normal. Lorelai agora está completa. Seu sorriso único, símbolo de sua beleza interior, destituído de qualquer poder diabólico, resplandesce ao lado de sua normalidade interior. (SIECZKOWSKI, 2004: 81-82)

A jovem que decidiu resignar-se em sua torre de marfim até que um homem a pedisse para ir com ele consegue a concretização de seu desejo quando é salva por um cirurgião, sendo então, "resgatada" não apenas pelo homem almejado, mas pelo fado que contribuiu para que seu "príncipe" fosse alguém capaz de curá-la de sua aparência.

Destino, determinismo, fado... são presenças constantes nas histórias maravilhosas, onde tudo parece determinado a acontecer, como uma fatalidade a que ninguém pode escapar. Muitos são os aspectos que essa fatalidade pode assumir: o de uma bruxa, de estrelas, de "voz não identificada", anjo do céu, feiticeiras (...) (COELHO, 2000: 178).

No conto Lorelai o fado determina seu crescimento deforme, sua feiúra, a qual a faz enclausurar-se em uma torre, porém combatida ainda por uma força pré-destinada, o príncipe de Lorelai, Fael, seu anjo salvador, cirurgião e marido, o homem que demanda e a salva, fazendo mágica por meio da medicina, tornando-a uma bela jovem, não mais deforme, e sim uma mulher irreconhecível, bela e apaixonada, retornando ao lar para encontrar seu povo que a adorava.

Em suma, observa-se que a narrativa Lorelai possui características semelhanças aos dos contos de fadas e por conseqüência, do gênero maravilhoso mesclando-se com fatos do cotidiano e ainda possuindo o famoso "e foram felizes para sempre" embutido no conto, afinal Lorelai casou-se com um belo rapaz e tornou-se rainha daquela vila. Há também marcas da modernidade, principalmente, na forma de chegada e partida das personagens e na maneira de resolução dos problemas por parte da protagonista, haja vista, a mudança de aparência da jovem que só pôde ser reconhecida por meio de seu sorrir.

\section{Referências bibliográficas:}

BERMAN, Marshall. Tudo que é sólido desmancha no ar: a aventura da modernidade. São Paulo: Cia das Letras, 1987.

CHIAMPI, Irlemar. O realismo maravilhoso. São Paulo: Perspectiva, 1980.

ECO, Umberto. Seis passeios pelos bosques da ficção. São Paulo: Cia das Letras, 1994. 
COELHO, Nelly Novaes. Literatura Infantil: Teoria, Análise e Didática. São Paulo: Moderna, 2000.

FURTADO, Filipe. A construção do fantástico na narrativa. Lisboa: Livros Horizonte, 1980.

GERONIMI, Clyde (dir.). A Bela Adormecida. Estados Unidos: Walt Disney, 1959.

LE GOFF, Jacques. O maravilhoso e o quotidiano no ocidente medieval. Trad. José António Pinto Ribeiro. Lisboa: Edições 70, 1985. p 19-37.

MÉNDEZ FERRÍN, X. L. "Lorelai”. In: Percival e outras historias. Vigo: Xerais, 1993.

PALMA, Glória Maria (org.). Literatura e Cinema: a demanda do Santo Graal \& Matrix/ Eurico, o presbítero \& A máscara do Zorro. Coleção Humus. São Paulo: Edusc, 2004.

RODRIGUES, Selma Calasans. O Fantástico. São Paulo: Ática, 1988.

SILVA, Adriana Camponogara Aires da. Aluna de Mestrado em Letras da UFSM. O maravilhoso na composição da história: Memorial do convento. Santa Maria, Rio Grande do Sul, 2007. Disponível em: http://www.ichs.ufop.br/conifes/anais/CMS/cms 0402.htm, visitado em: 08/08/2008 às 16h58min.

SIECZKOWSKI, L. F. "Lorelai". In: GARCÍA, F. (org.). Ler Ferrín; ler Galiza: estudos literários. Rio de Janeiro: Dialogarts, 2004. p. 77- 83. Disponível em: http://www.dialogarts.uerj.br/arquivos/ler_ferrin.pdf.

TATAR, Maria. Contos de Fadas: “Rapunzel”. Edição comentada e Ilustrada/ Edição, Introdução e Notas; Tradução: Maria luiza X. de A. Borges. Rio de Janeiro: Zahar,2004.

TODOROV, Tzvetan. Introdução à literatura fantástica. Trad. Maria Clara C. Castelo. São Paulo: Perspectiva, 1975. 